\title{
Students' Self-directed Learning in the Context of Industrial Challenges: Latvia University of Life Sciences and Technologies \\ Case
}

\section{Baiba Briede}

Institute of Education and Home Economics, University of Life Sciences and Technologies, Latvia

\begin{abstract}
Students' self-directed learning (SDL) is analysed as a means to promote the development of professionals who are active life-long learners, ready to complex problem solving, leadership and flexible adaptation to social and economic situations. That is why the aim of the study was to analyse the components of SDL essential for nowadays socio-economic situation and to find out SDL results from the students of Latvia University of Life Sciences and Technologies (LLU). The method of questionnaire was used to investigate the students' self-assessment on their SDL focusing on purposefulness, motivation for knowledge, implementation of effective learning strategies, responsibility, control assessment of learning progress, importance to express one' $s$ view and time management. The results of the study were obtained from 305 first-year students of LLU. Medium results dominate in relation to implementation of effective learning strategies, importance to express one's view and time management. It means that preferably an electronic aid on learning strategies and more flexible learning environments for the first year students is necessary. The study results also indicate that more teaching methods promoting views expression are of high importance and should be included in further education courses for teachers.
\end{abstract}

Keywords: Self-directed learning; university students; professionalism. 


\section{Introduction}

The study of self-directed learning (SDL) is topical because this process depends on socioeconomic changes in the world having an impact on the demands in higher education. The situation is that not all students are ready for self-directed studies because getting of higher eduction is very popular among young people but not all of them are motivated for deep and research-based studies. Therefore it is necessary to find solutions how to promote students' learning considering self-directed studies indicators.

That is why both theoretical and practical assessment of SDL understanding, components and cases is necessary considering the statements of European Higher Education Area (EHEA) and on global processes. The study covered the conclusions of Bologna process ministers meetings, World Economic Forum 2018 and researches of teaching/learning in higher education.

Ten aspects as competitiveness, investing in people, globalization, open economies, innovation ecosystems, development of technologies and institutions, infrastructure and the financial system, constant change and agility, equality, sustainability and growth together are relevant for governments in the fourth industrial revolution (World Economic Forum, 2018). They relate to social, economic, ecological situation in nowadays world and mark the directions important to consider in the education of future oriented, flexible, competent and proactive specialists.

Forthcoming specialists mainly are tended to find their place in a labour market and that is why students' SDL is focused on professional development. Both labour market and professional development are dynamic concepts influenced by demands of society, technological progress, ecology and development of industries and trade. Students need clear understanding of both concepts and their changeable character in today's situation, in the nearest and further future to guide their SDL purposefully.

That is why the aim of the study was to analyse the components of SDL essential for nowadays socio-economic situation and to find out SDL results from the students of Latvia University of Life Sciences and Technologies.

\section{Research methodology}

The theoretical studies on professional and SDL development, and perspectives, cognitions of future skills for the labour market put forward by World Economic Forum 2018 and topical learning outcomes defined by Bologna process Paris meeting in 2018 had been carried out. 
There were ranged the data $(\mathrm{R})$ and their distribution got from the first year LLU students taking the highest level answers as an accounting point.

The method of questionnaire to investigate 305 LLU first year students' self-assessment on the development of SDL had been carried out in autumn 2018.

Respondents represented the fields of agriculture, forestry, veterinary medicine, economics, food technology, engineering, landscape architecture, land survey and information technologies.

Students marked high (h), medium (m) and low (l) level of purposefulness, motivation for knowledge, implementation of effective learning strategies, responsibility, control assessment of learning progress, importance to express one's view and time management.

The obtained results can be used in making an electronic learning aid for students and revising the courses for LLU academic staff and implementation of methods and content promoting better reaching of learning outcomes.

\section{Theoretical results}

The concept of professional development is analysed in every decade and it reflects the nature of the epoch. Professionalism should be proved and it means that a person has to demonstrante it. According to D. Schön (1983) it is possible to determine such key words for professional's action as "creative approach", "practical experience in a highly intuitive manner", "reflection” on things being done which is summarized in „reflection-in-action”. This kind of reflection happens immediately in action and involves critical thinking and it is ,...to some measure conscious”. Demonstration of competence in creative work requiring situations involves practical experience in combination with intuition and reflection during action.

K. Paechter $(1996,347)$ more than two decades ago in her study on professional development mentioned that "Professionals know what they are doing - they have expertise. They have usually undergone some training or at least undertaken extensive practice of their skills and development of their knowledge". It is also mentioned that the professionals are not always tested in examinations but it is possible "to exclude some individuals from further membership, on specific grounds such as incompetence or dishonesty". K. Paechter (1996, 247) also relates to the professionals such key words as "get paid what they do", ethics, "autonomous action" and "carry out their work in an emotionally neutral manner".

The situation today is that we are in the period of the Fourth Industrial Revolution (4IR) and it draws corrections in the understanding of professionalism as well. The main features of the 4IR are digital technologies, smart industries with such basic elements as IT and 
artificial intelligence (AI). K.Schwab (2016) mentions that the challenges for humans are management of smart devices and technologies, adaptation to quick changes of them and not to become robotised as well as humans need to develop creativity, empathy and stewardship.

World Economic Forum (WEF) (2018) named 10 top skills in the labour market after 2022, for example, analytical thinking and innovation, active learning and learning strategies and complex problem-solving. They point to the development of autonomous personality able to act appropriately in changing and complex situations when a rapid development of innovations including technologies and artificial intelligence is going on. The skills put forward by WEF 2018 meets the investigation results by Deloitte Global CEO (Preparing tomorrow's workforce..., 2019, 16) where four main skill categories as workforce readiness, soft skills, technical skills and entrepreneurship relevant for the 4IR are stated. Life-long learning as a "continuous process of gaining new knowledge and skills as individuals progress through their professional and personal careers" unites all the four skills categories.

The stated skills is a big challenge for educators in higher education because it is necessary to understand the processes in labour market and forecasts of workforce strategy. It means that higher education has to promote the development of professionals who are active lifelong learners, ready to reskilling, leadership and flexible adaptation to social and economic situations.

Ministerial Conference Paris (2018) published revised learning outcomes in the Qualifications Framework for EHEA comprising the qualifications from the short to the third cycle. In the short cycle readiness to further education and employment capabilities are particularly emphasized. In the second cycle professional approach as well as "ability to integrate knowledge and handle complexity, and formulate judgements with incomplete and limited information". A special attention should be paid to the first and second cycle qualifications focusing on learning outcomes justification with SDL. These two qualification levels include the largest mast of students which will meet labour markets demands and SDL should be an actual tool reach better learning outcomes and be successful in labour market.

Considering the ideas from the last three decades it is possible to derive several dimensions of professional development: skilfulness in the field with tendency to receive an expert level; autonomous action; life-long learning; social skilfulness; ability to adapt to social and work situations; ethics in work and social situations; creativity; divergent and convergent thinking; innovations. The dimensions could be as milestones to make SDL more focused. 
SDL as autonomous and necessary skill for the $21^{\text {st }}$ century is investigated by a lot of higher and adult education researchers (Cox, 2015; Giddings, 2015; Guglielmino, 2013; Henschke, 2016; Wilcox, 1996).

SDL means a teacher's democratic position and values, usage a lot of teaching strategies as well as creating a situation that students feel free and are not afraid to make mistakes. "Self-directed learning as an instructional method, as previously mentioned, like any method or pedagogy, is likely adopted based on the professor's personal values or preferences for instruction. This is where self-directed learning becomes a teaching philosophy" (Cox, 2015, 22).

Development of experiential learning could be a serious contribution to the process of SDL. According to Escalante \& Aguilar-Barrientos (2017) it comprises critical and creative thinking. Those two qualities play an important role in autonomous and initiative behavior and can be promoted by interactive methods and formative assessment.

SDL is a means to prepare oneself for changing life conditions. At the same time the components of SDL have to be revised because forecasts of dynamic social and economic changes have to assessed and integrated into comprehension of SDL. The process of SDL is two-sided. Students have to be active assessing their learning outcomes which are understood as knowledge, skills and competence, and the process of learning including cognition, activity, purposefulness, learning strategies and problem-solving from one side. The students also have to be active followers of world's socio-economic processes and they have to develop the qualities helping them to be successful professionals in the processes of the changing labour market from the other side.

Considering the present socioeconomic situation SDL is a process where students are purposeful, with initiative and responsibility controlling and assessing the progress of their learning outcomes. The students are autonomous learners able to carry out effective learning strategies, manage time and understand the importance of life-long learning.

The key phrases and words of: the future labour market demands towards a professional's skills, professional development, learning outcomes of the first cycle qualifications and SDL are reflected in Table 1 with the purpose to find out conjunctive elements and incompatibilities. The comparison will help to complete SDL and make it a better tool for reaching learning successes and be ready for labour market demands. 
Table 1. Key words and phrases for professionalism, learning outcomes and SDL

\begin{tabular}{|c|c|c|}
\hline Professionalism & $\begin{array}{l}\text { Learning outcomes (Ministerial } \\
\text { Conference Paris (2018) }\end{array}$ & SDL \\
\hline $\begin{array}{l}\text { usage of experience; } \\
\text { reflection in action (Schön } \\
\text { 1983); } \\
\text { ethics in work and social } \\
\text { situations; } \\
\text { autonomous action; } \\
\text { life-long learning; } \\
\text { from skillfulness to expertise; } \\
\text { rapid adaptation to smart } \\
\text { technologies and reskilling; } \\
\text { stewardship; } \\
\text { flexible adaptation to social, } \\
\text { work and economic situations; } \\
\text { analytical thinking; } \\
\text { creating innovations; } \\
\text { social skilfulness; } \\
\text { analytical, systemic, critical } \\
\text { thinking and innovation; } \\
\text { complex problem-solving; } \\
\text { creativity; }\end{array}$ & $\begin{array}{l}\text { ability to integrate knowledge and } \\
\text { handle complexity; } \\
\text { formulate judgements with incomplete } \\
\text { and limited information; } \\
\text { apply knowledge and understanding in a } \\
\text { manner that indicates a professional } \\
\text { approach to work or vocation; } \\
\text { have competences through devising and } \\
\text { sustaining arguments and solving } \\
\text { problems within their field of study; } \\
\text { have the ability to gather and interpret } \\
\text { relevant data including reflection on } \\
\text { relevant social, scientific or ethical } \\
\text { issues; } \\
\text { can communicate information, ideas, } \\
\text { problems and solutions to both } \\
\text { specialist and non-specialist audiences; } \\
\text { have developed those learning skills that } \\
\text { are necessary for them to continue to } \\
\text { undertake further study with a high } \\
\text { degree of autonomy }\end{array}$ & $\begin{array}{l}\text { critical and creative } \\
\text { thinking; } \\
\text { experiental learning; } \\
\text { controlling and } \\
\text { assessing learning } \\
\text { progress; } \\
\text { skillful usage of } \\
\text { learning strategies; } \\
\text { problem-solving; } \\
\text { active following of } \\
\text { world's socio- } \\
\text { economic processes; } \\
\text { expressing views; } \\
\text { autonomous learners; } \\
\text { manage time; } \\
\text { understand the } \\
\text { importance of life- } \\
\text { long learning; } \\
\text { purposeful learner; } \\
\text { with initiative; } \\
\text { responsible learner }\end{array}$ \\
\hline
\end{tabular}

Indicators of professionalism and learning outcomes highlight the actual focus of learning and there is a conjunction among them because their nature correspond to each other or even coincide. SDL indicators also correspond and therefore they function as an actual tool for reaching the learning outcomes and higher professionalism. But at the same time they should be analysed and revised because they depend on ideas of the development of professionalism and labour market demands. 
The promotion of SDL in the situation of the Fourth Industrial Revolution can be carried out using:

- flexible group work learning environments in lecture-rooms and corridors promoting both formal and informal learning, and expressing of views;

- $\quad$ learning through Moodle environment, YouTube, blogs, video games;

- diversified education programmes considering labour market topicalities and involving practitioners in contact hours;

- teaching/learning methods focused on innovations and outcomes (knowledge, skills and competence) based learning.

\section{Empirical study}

The questionnaire of 305 first-year students took part in October and November 2018. Results are ranged considering the frequency of answers in the highest level (Table 2).

The first two question were about the students' purposefulness and motivation to reach better learning outcomes. Correspondingly 230 and 208 students assessed that indicator as high and 75 and 96 students - medium. Low assessments were not for those indicators except one student. The students comments were both motivation as necessity to get deeper knowledge and become a competent professional and stimuli as good work, free of charge studies, a scholarship. A part of students marked that they are purposeful only in individual courses.

Students marked mainly high and medium assessments also in the question about their responsibility towards learning (154 answers - high and 147 - medium and 4 - low). Many students recognised that they could be more responsible towards learning but there are such obstacles as laziness, many interesting outdoor activities and lack of motivation. 
Table 2. First-year students' assessments of SDL.

\begin{tabular}{|c|c|c|c|c|c|c|c|}
\hline \multirow[t]{4}{*}{ No. } & \multirow[t]{4}{*}{ Indicator } & \multicolumn{3}{|c|}{ Assessment grade } & \multirow[t]{4}{*}{$\mathbf{R}_{\text {high }}$} & \multirow[t]{4}{*}{$\Sigma_{1+2}$} & \multirow[t]{4}{*}{$\mathbf{R}_{\mathbf{1 + 2} 2}$} \\
\hline & & high & medium & low & & & \\
\hline & & \multicolumn{3}{|c|}{$\mathbf{R}$} & & & \\
\hline & & $\mathbf{1}$ & 2 & 3 & & & \\
\hline 1. & $\begin{array}{l}\text { Purposefulness to } \\
\text { reach better learning } \\
\text { outcomes }\end{array}$ & 230 & 75 & 0 & 1 & 305 & 1 \\
\hline 2. & $\begin{array}{l}\text { Motivation for } \\
\text { knowledge }\end{array}$ & 208 & 96 & 1 & 2 & 304 & 2 \\
\hline 3. & Responsible learning & 154 & 147 & 4 & 4 & 301 & 3 \\
\hline 4. & $\begin{array}{l}\text { Implementation of } \\
\text { effective learning } \\
\text { strategies }\end{array}$ & 92 & 198 & 15 & 5 & 290 & 5 \\
\hline 5. & $\begin{array}{l}\text { Control and assessment } \\
\text { of learning progress }\end{array}$ & 160 & 137 & 8 & 3 & 297 & 4 \\
\hline 6. & $\begin{array}{l}\text { Importance to express } \\
\text { a view }\end{array}$ & 88 & 171 & 46 & 6 & 259 & 7 \\
\hline 7. & $\begin{array}{l}\text { Time management to } \\
\text { reach better learning } \\
\text { outcomes }\end{array}$ & 73 & 190 & 42 & 7 & 263 & 6 \\
\hline
\end{tabular}

Students were asked about their skills to use learning strategies effectively. There the medium answers dominated (198 answers) and only 92 students assessed that indicator as high, and 15 said that learning skills are low. The students commented that they try to use and even investigate which learning strategies could be better for them and they recognise that they are successful. At the same time most of the students comment that they have adaptation and e-learning difficulties, they are quite chaotic and do not know how to learn more effectively.

Students positively relate to control and assessment of their learning progress and more than a half of students (160) mark high level of this indicator but there are also 137 answers for medium level and eight for low level. The students comment that they assess their progress or do it episodically. It is worth mentioning that the students are only at the beginning of their university learning but this indicator shows also their habits from the secondary education. 
Expression of one's view and time management is a problem for many students with medium assessment dominance. The students answer that they are timid, critical towards themselves and do not feel competent to speak. It means that group work methods and problem-based learning have to be more expanded during contact hours and project works.

Time management problems solving can be solved educating students and academic staff both theoretically and practically including the themes in social courses.

\section{Conclusions}

SDL can be effective if it corresponds the indicators of professionalism and learning outcomes that is why labour market and professionalism traits should be followed up constantly. Learning outcomes and SDL should be revised regularly because they depend on ideas of the development of professionalism and labour market demands.

As SDL is a complicated process consisting of various indicators affecting factors should be analysed and assessed in further investigations. Purposefully managed self-directed university studies are highly important because they put a stress on each student's higher responsibility, initiative, motivation, independence, collaboration and self-assessment. Students control and assess their learning steps. Teachers should provide a high level lecturing and advising.

The questionnaire results serve as a means of revision of the students' and academic staff understanding of SDL. Continuous development and support of SDL components promote the quality of learning and understanding of the individual's human capital opportunities in the frame of competence oriented systemic studies.

Regular investigations of students' SDL help to assess which indicators should be improved and what teaching/learning aids to develop. Medium results dominate in relation to implement effective learning strategies, importance to express one's view and time management. It means that preferably an electronic aid on learning strategies for the first year students is necessary. The study results also indicate that more teaching methods promoting one's views expression are of high importance and should be more expanded in the further education courses for academic staff.

\section{References}

Cox, T. D. (2015). Adult Education Philosophy: The Case of Self-Directed Learning Strategies in Graduate Teaching. Journal of Learning in Higher Education, 11 (1), $17-$ 22. 
Escalante, J.E \& Aguilar-Barrientos, S. (2017). The CAMBRIA case: Learning through experience. 3rd International Conference on Higher Education Advances (HEAd'17), 726 -733. doi: 10.4995/HEAd17.2017.6713.

Giddings, S. (2015). Self-Directed Learning (SDL) in Higher Education: A Necessity for $21^{\text {st }}$ Century Teaching and Learning. Ontario: Faculty of Education, Brock University. Retrieved from https://www.researchgate.net/publication/277009137_SelfDirected_Learning_SDL_in_Higher_Education_A_Necessity for_21st_Century Teachi $\underline{\text { ng and Learning }}$

Guglielmino, L. M. (2013). The Case for Promoting Self-Directed Learning in Formal Educational Institutions. SA-eDUC Journal. 10(2). Retrieved from http://www.nwu.ac.za/sites/www.nwu.ac.za/files/files/psaeduc/sdl\%20issue/Guglielmino\%2C\%20L.M.\%20The\%20case\%20for\%20promoting \%20self-directed\%20lear.pdf

Henschke, J.A. (2016). Self-Directed Learning [SDL] and Andragogy: My Take on Their Contrasting and Complementary Relationship. Knoxville: University of Tennessee. Retrieved from https://trace.tennessee.edu/cgi/viewcontent.cgi?referer=\&httpsredir=1\&article=1483\&c ontext=utk_IACE-browseall

Ministerial Conference Paris. (2018). The Framework of Qualifications for the European Higher Education Area. Paris: Ministerial Conference Paris. Retrieved from http://www.ehea.info/media.ehea.info/file/2018_Paris/77/8/EHEAParis2018_Communi que_AppendixIII_952778.pdf

Paechter, C. (1996). What Do We Mean by Profesional Development? Research in PostCompulsory Education, 1 (3), 345-355, doi: 10.1080/1359674960010305

Preparing tomorrow's workforce for the Fourth Industrial Revolution. For business: A framework for action. (2018). Deloitte Global CEO. Retrieved from https://gbceducation.org/wp-content/uploads/2018/09/Deloitte_GBC_Brochure_V3 17Sep.pdf

Schön, D. (1983). The Reflective Practitioner: How Professionals Think in Action. London, Temple Smith

Schwab, K. (2016). The Fourth Industrial Revolution: What it means, How to Respond. World Economic Forum. Retrieved fom: https://www.weforum.org/agenda/2016/01/the-fourth-industrial-revolution-what-itmeans-and-how-to-respond/

Wilcox, S. (1996). Fostering Self-Directed Learning in the University Setting. Studies in Higher Education, 21(2). Retrieved from http://web.mit.edu/jrankin/www/self_direct/self_dir_univ1.html

World Economic Forum. (2018). 10 things you - and your government - should know about competitiveness in the Fouth Industrial Revolution. Geneva:World Economic Forum. Retrieved from https://www.weforum.org/agenda/2018/10/10-things-you-andyour-government-should-know-about-competitiveness-in-the-fourth-industrialrevolution/

World Economic Forum. Centre for the New Economy and Society. (2018). The Future of Jobs Report. Geneva: World Economic Forum. Retrieved from http://www3.weforum.org/docs/WEF_Future of Jobs_2018.pdf 